\title{
A Theoretical Kinetic Study on the Reaction of Atomic Bromine with Toluene
}

\author{
Binod Raj Giri*1, John M. Roscoe ${ }^{2}$, Milán Szőri ${ }^{3}$ and Aamir Farooq ${ }^{1}$
}

${ }^{1}$ King Abdullah University of Science and Technology (KAUST), Clean Combustion Research Center, Division of Physical Sciences and Engineering, Thuwal 23955-6900, Saudi Arabia

${ }^{2}$ Department of Chemistry, Acadia University, Wolfville, Nova Scotia, B4P 2R6, Canada

${ }^{3}$ Institute of Chemistry, Faculty of Materials Science and Engineering, University of Miskolc, H-3515 Miskolc-Egyetemváros, A/2, Hungary

* Corresponding Author: Binod Raj Giri email: Binod.Giri@kaust.edu.sa 


\begin{abstract}
The reaction of $\mathrm{Br}$ atoms with toluene was investigated by employing various quantum chemical methods and statistical rate theory calculations. Various composite methods such as CBS-QB3, G3 and G4 were used to obtain the energy profiles of the $\mathrm{Br}+$ toluene reaction. Further singlepoint calculations of the stationary points were performed at the $\operatorname{CCSD}(\mathrm{T}) / \mathrm{cc}-\mathrm{pV}(\mathrm{D}, \mathrm{T}) \mathrm{Z}$ level of theory using B3LYP/cc-pVTZ and MP2/aug-cc-pVDZ optimized geometries. Our calculations revealed several reaction pathways in the potential energy surface of the $\mathrm{Br}+$ toluene reaction. However, the reaction pathway that abstracts hydrogen atoms from the methyl site of toluene was found to be energetically the most favorable. This reaction pathway appears to proceed via a complex forming mechanism, similar to that seen in the reactions of cyclic ethers with $\mathrm{Br}$ atoms. Our calculations reveal that the reaction of a $\mathrm{Br}$ atom with toluene proceeds exclusively via intermediate complexes in an overall endothermic addition-elimination mechanism. Based on the $a b$ initio results, the standard enthalpies of formation of the product radicals and the rate coefficients for the relevant reaction pathways are computed. The calculated values of the enthalpy of formation are found to match excellently with the available literature data. Lowering the barrier height of hydrogen abstraction reaction at the methyl site by less than $4 \mathrm{~kJ} / \mathrm{mol}$, the calculated rate coefficients, $k_{o v} .(T)=1.36 \times 10^{-23} T^{3.68} \exp (-4.57 \mathrm{~K} / T) \mathrm{cm}^{3}$ molecule ${ }^{-1} \mathrm{~s}^{-1}$, reproduced the experimental data excellently from 200 to $500 \mathrm{~K}$.
\end{abstract}




\section{Introduction}

It was realized in the early 1970s that halogen atom chemistry was important for understanding atmospheric issues such as ozone depletion. ${ }^{1}$ By the 1980 s it had become clear that bromine (Br) atom chemistry was important in ozone depletion events in the Arctic. ${ }^{2,3}$ These observations sparked extensive research in the kinetics of halogen atom reactions which led to a large database of kinetic data for halogen atom reactions. ${ }^{4-7}$ In recent years, there have been several reviews of atmospheric halogen atom chemistry. ${ }^{8-11}$ Much of the work has focused on reactions of halogen atoms with hydrocarbons near ambient temperature and pressure. Interestingly, more attention has been paid to the reactions of atomic chlorine than to the reactions of atomic bromine despite its importance to atmospheric chemistry in the Arctic. In fact, volatile organic compounds (VOCs) display a large variation in their reactivity towards $\mathrm{Br}$ atoms in contrast to their reactions with chlorine atoms (see Giri et al. ${ }^{12}$ and references cited therein). Therefore, it is important to have mechanistic information on the kinetics of reactions of atomic bromine with a wide variety of VOCs. Moreover, knowledge of the temperature-dependence of the rate coefficients of the reactions of $\mathrm{Br}$ with VOCs would enable applications over the range of temperatures encountered in the atmosphere. This would also permit a more detailed interpretation of the dynamics of the interaction of $\mathrm{Br}$ with an organic reactant.

We have been engaged for several years to measure the temperature dependence of reactions of atomic bromine with ethers ${ }^{12-17}$ to achieve some of these objectives. We selected ethers because these are widely used for industrial applications ranging from solvents to fuel additives and are, therefore, released into the atmosphere. Interpretation of the experimental results has been greatly enhanced by the application of computational chemistry which has allowed identification of the lowest energy reaction paths for the reactions. ${ }^{12-14}$ All reactions of Br that we studied had modest 
activation energies. In general, the reactions of $\mathrm{Br}$ with the ethers were found to involve three stages. The initial interaction of $\mathrm{Br}$ with ethers is exothermic, barrierless formation of a loosely bound pre-reaction complex involving the ether oxygen atom. The second stage involves conversion of this pre-reaction complex to a pre-dissociation complex before eliminating $\mathrm{HBr}$. This requires a significant energy barrier rising somewhat above the energy of the reactants. In the case of 1,4-dioxane, this stage requires two steps, each with an energy barrier. The extent to which the barrier in this second stage rises above the energy of the reactants is significantly reduced by the exothermicity of the formation of the initial adduct. The third stage is the barrierless elimination of $\mathrm{HBr}$. The rate coefficients calculated from the potential energy surface results were in excellent agreement with the experimental results. In a complementary study, we measured the rate coefficients for the reactions of atomic chlorine with 1,4 -dioxane. ${ }^{18}$ Once again, the computational results were in excellent agreement with the experimental results, and provided a convincing explanation for the lack of activation energy for the reaction of $\mathrm{Cl}$ with 1,4-dioxane.

The success of our experimental and theoretical analysis of the reactions of $\mathrm{Br}$ with ethers encouraged us to extend this work to analyze the reaction of $\mathrm{Br}$ atoms with aromatic compounds. In an earlier study ${ }^{16}$, we found that the reaction of $\mathrm{Br}$ with ethylene produced very little $\mathrm{HBr}$ while the reactions of Br with 2-methyl propane, dimethyl ether and diethyl ether produced large yields of $\mathrm{HBr}$. This led us to conclude that elimination of $\mathrm{HBr}$ from the bromoethyl free radical formed in the initial interaction of $\mathrm{Br}$ with ethylene is not energetically feasible compared to other possible fates such as the formation of 1,2-dibromoethane by reaction of this free radical with excess $\mathrm{Br}_{2}$. These observations motivated us to assess the importance of formation of an initial complex between an aromatic compound and $\mathrm{Br}$. 
Recently, we have measured the rate coefficients for the temperature dependence of the reactions of $\mathrm{Cl}$ with xylenes and toluene ${ }^{19}$ and $\mathrm{Br}$ with toluene ${ }^{15}$. The rate coefficients for these reactions did not show any statistically significant dependence on temperature. They were close to the collision limit, $\sim 10^{-10} \mathrm{~cm}^{3}$ molecule-1 $\mathrm{s}^{-1}$, and exhibited similar reactivity to that of the reactions of other VOCs with $\mathrm{Cl}$ atoms ${ }^{20,21}$. The reactions of $\mathrm{Cl}$ with xylenes yielded an average rate coefficient of $(1.4 \pm 0.3) \times 10^{-10} \mathrm{~cm}^{3}$ molecule $\mathrm{e}^{-1} \mathrm{~s}^{-1}$ at $298 \mathrm{~K}$, showing no dependence on xylene isomer, while the rate coefficient for the reaction of $\mathrm{Cl}$ with toluene was $(5.0 \pm 0.6) \times 10^{-11} \mathrm{~cm}^{3}$ molecule ${ }^{-1} \mathrm{~s}^{-1}$. Here, the difference in the reactivity of toluene and xylenes with $\mathrm{Cl}$ atoms stems from the difference in the statistical factor. This suggests that the barrierless addition of a $\mathrm{Cl}$ atom to VOCs in the entrance channel is the rate determining step. On the contrary, the reactions of $\mathrm{Br}$ with these aromatics display some variations in their reactivity. ${ }^{22}$ Such behavior may be largely due to the variation of the potential barrier of the inner transition states along the reaction pathway. There was evidence in the literature ${ }^{22}$ that the reaction of benzene with $\mathrm{Br}$ was unmeasurably slow, suggesting that the abstraction of a ring hydrogen was unimportant. In our earlier experimental work, ${ }^{15}$ we found that the reaction of $\mathrm{Br}$ with toluene occurred with a conveniently measurable rate coefficient. This suggested that the bromine atom reacted primarily with the methyl hydrogens. Here, we apply computational chemistry methods to analyse the detailed dynamics of the reaction of $\mathrm{Br}$ with toluene to assess the importance of intermediate complexes in determining the kinetics of this reaction and to investigate the validity of our assessment that the abstraction of a methyl hydrogen atom is the dominant reaction path. 


\section{Computational Methods}

Structures and Energies. The potential energy surface (PES) describing the reaction of $\mathrm{Br}$ atoms with toluene was computed using composite methods (CBS-QB3, G3 and G4). More sophisticated thermochemical protocols such as Weizmann-1 and CBS-APNO are not applicable to Br-containing species due to the limitations in the basis sets. The structures of all species involved in the low-energy reaction pathways were reoptimized by applying the tight convergence criterion to the second-order Møller-Plesset (MP2) ${ }^{23}$ perturbation theory and Becke-3 Lee-Yang-Parr (B3LYP) functional ${ }^{24-26}$ using all electrons Dunning's correlation-consistent double- $\zeta$ and triple$\zeta$ basis sets ${ }^{27-30}$ for $\mathrm{C}, \mathrm{H}$ and $\mathrm{Br}$. The optimized structures were further characterized by normal mode analysis to distinguish their identity on the PES. The harmonic vibrational frequencies obtained at the MP2/aug-cc-pVDZ and B3LYP/cc-pVTZ levels of theory were scaled by a factor of 0.9615 and 0.967 , respectively. ${ }^{31}$ The scaled vibrational frequencies were then used for calculation of thermodynamic properties and rate coefficients. The reliability of the calculated rate coefficients depends strongly upon the accuracy of the energy barriers. Therefore, the energetics of the minimum energy pathway of the toluene $+\mathrm{Br}$ reaction were further refined by performing single-point coupled-cluster calculations with single and double excitations including the perturbative treatment of triple excitations $(\operatorname{CCSD}(\mathrm{T}))^{32-35}$ using the optimized geometries at the MP2/aug-cc-pVDZ and B3LYP/cc-pVTZ levels of theory. Using the asymptotic form suggested by Martin ${ }^{36}$ and by Dixon and Feller ${ }^{37}, \operatorname{CCSD}(\mathrm{T})$ energies were obtained by extrapolation to the complete basis-set limit $(\mathrm{CBS}): E_{\mathrm{CBS}}=E_{l_{\max }}-B /\left(l_{\max }+1\right)^{4}$, where $l_{\max }$ is the maximum component of angular momentum in the cc-pVXZ basis set, and $E_{\mathrm{CBS}}$ is the infinite basis-set energy. In this study, cc-pVXZ $(X=\mathrm{D}, \mathrm{T})$ basis sets were used, i.e., $l_{\max }=2,3$. $E_{\mathrm{CBS}}$, which can also be denoted as the $\operatorname{CCSD}(\mathrm{T}) / \mathrm{cc}-\mathrm{pV}(\mathrm{D}, \mathrm{T}) \mathrm{Z}$ level of theory, should provide an accurate 
energetic description of the $\mathrm{Br}$ atom reaction with toluene. The frozen core approximation was applied for all $\operatorname{CCSD}(\mathrm{T})$ calculations. To assess the contribution of higher excitations, $T_{1}$ $\operatorname{diagnostics}^{38}$ were computed. For toluene, the $T_{1}$ value was found to be 0.01 , whereas they were less than $\sim 0.03$ for all the open shell species suggesting that the chemical system investigated here is dominated by dynamical correlations. ${ }^{39,40}$ Therefore, single reference methods are adequate for an accurate energetic description of the $\mathrm{Br}+$ toluene reaction.

All electronic structure calculations were performed by using the Gaussian 09 program package 41. The results of the electronic structure calculations (derived molecular parameters, optimized geometrical parameters, thermochemical data in JANAF Table and NASA format) are compiled in Tables S1-S5 of Supplementary Materials (SM). The optimized geometric parameters for selected species are provided in Figure 1 and Table 1. The ab initio results were used to assess the importance of various reaction pathways in the $\mathrm{PES}$ of the $\mathrm{Br}+$ toluene reaction. The characteristic points of the PES were used to deduce the mechanism of the $\mathrm{Br}+$ toluene reaction. While mapping out the PES, intrinsic reaction coordinate (IRC) calculations ${ }^{42,43}$ were also performed at the MP2/aug-cc-pVDZ level of theory to ensure that the transition state ( $\mathrm{TS}_{\text {methyl-abs }}$ ) appropriately connects the intermediate complexes, the pre-reaction complex (RC) at the reactant side and the post-reaction complex (PC) at the products side. 


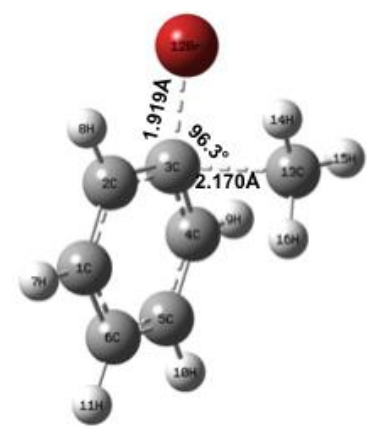

$\mathrm{TS}_{\text {methyl-subs }}$

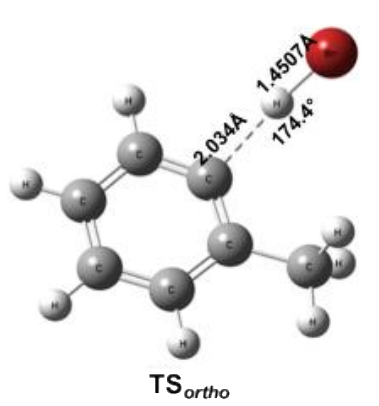

$\mathrm{TS}_{\text {ortho }}$

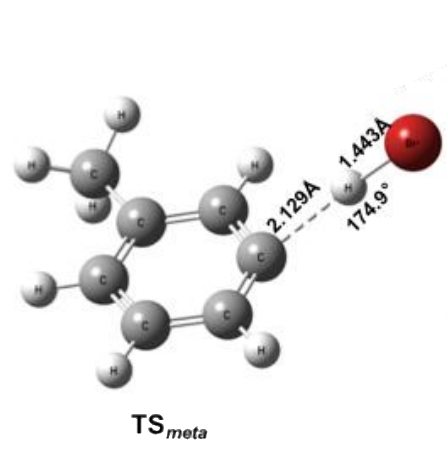

$\mathrm{TS}_{\text {meta }}$

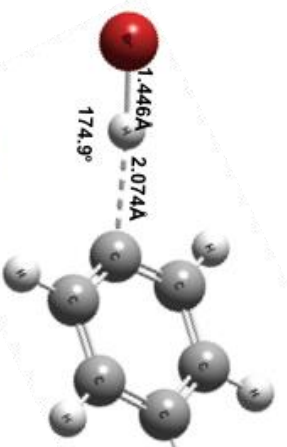

6

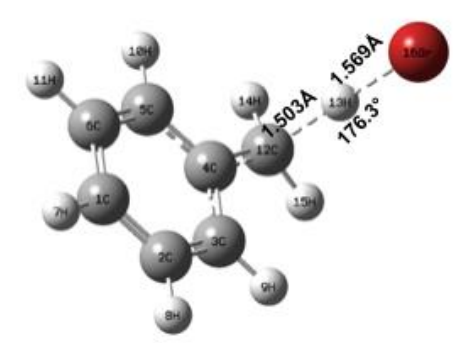

$\mathrm{TS}_{\text {methyl-abs }}$

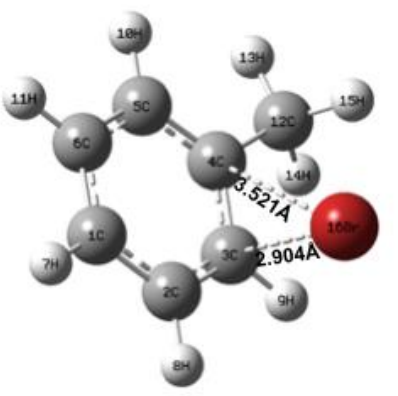

RC

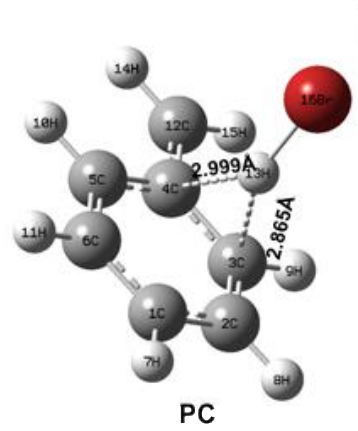

Figure 1: Geometric parameters of selected species obtained at the MP2(full)/6-31G(d) level of theory within the G3 thermochemical protocol. TS, RC and PC stand for the transition state, prereaction complex and post-reaction complex. The subscript identifies the transition state responsible for the undergoing chemical reaction of toluene $+\mathrm{Br}$.

Table 1: Equilibrium geometry of selected species obtained by employing five different quantum chemical methods. Bond lengths $(r)$ and bond angles $(\delta)$ are in Angstroms and degrees, respectively. $v^{*}$, in units of $\mathrm{cm}^{-1}$, is the imaginary frequency of the transition state for hydrogen abstraction from the methyl group ( $\left.\mathrm{TS}_{\text {methyl-side }}\right)$.

\begin{tabular}{|c|c|c|c|c|c|c|c|c|c|c|c|}
\hline Species $\rightarrow$ & \multicolumn{3}{|c|}{$\mathbf{R C}$} & \multicolumn{4}{|c|}{$\mathbf{T S}_{\text {methyl-abs }}$} & \multicolumn{4}{|c|}{ PC } \\
\hline Level of Theory $\downarrow$ & $\begin{array}{l}r(\mathrm{Br}- \\
\mathrm{C} 3)\end{array}$ & $\begin{array}{l}r(\mathrm{Br}- \\
\mathrm{C} 4)\end{array}$ & $\begin{array}{l}\delta(\mathrm{C} 4- \\
\mathrm{C} 3-\mathrm{Br})\end{array}$ & $\begin{array}{l}r(\mathrm{C} 12- \\
\mathrm{H} 13)\end{array}$ & $\begin{array}{l}r(\mathrm{H} 13- \\
\mathrm{Br})\end{array}$ & $\begin{array}{l}\delta(\mathrm{C} 12- \\
\mathrm{H} 13-\mathrm{Br})\end{array}$ & $v^{\star}$ & $\begin{array}{l}r(\mathrm{C} 4- \\
\mathrm{H} 13)\end{array}$ & $\begin{array}{l}r(\mathrm{C} 3- \\
\mathrm{H} 13)\end{array}$ & $\begin{array}{l}r(\mathrm{H} 13- \\
\mathrm{Br})\end{array}$ & $\begin{array}{l}\delta(\mathrm{C} 3- \\
\mathrm{H} 13-\mathrm{Br})\end{array}$ \\
\hline $\begin{array}{l}\text { CBS-QB3 } \\
(\text { B3LYP/6-311G(2d,d,p)) }\end{array}$ & 2.771 & 3.305 & 99.1 & 1.560 & 1.563 & 173.9 & 482 & 3.111 & 2.592 & 1.431 & 165.3 \\
\hline $\begin{array}{l}\text { G3 } \\
\text { (MP2(full)/6-31G(d)) }\end{array}$ & 2.904 & 3.521 & 104.1 & 1.503 & 1.568 & 176.3 & $1579 *$ & 2.999 & 2.865 & 1.435 & 135.2 \\
\hline $\begin{array}{l}\text { G4 } \\
(\text { B3LYP/6-31G(2df,p)) }\end{array}$ & 2.731 & 3.271 & 99.2 & 1.580 & 1.553 & 175.0 & 353 & 2.994 & 2.497 & 1.432 & 169.9 \\
\hline MP2/aug-cc-pVDZ & 2.787 & 2.806 & 76 & 1.439 & 1.581 & 176.4 & 877 & 2.594 & 2.407 & 1.431 & 162.4 \\
\hline B3LYP/cc-pVTZ & 2.765 & 2.306 & 99.4 & 1.542 & 1.571 & 174.6 & 527 & 3.769 & 3.476 & 1.431 & 145.7 \\
\hline
\end{tabular}

* The harmonic wavenumber was calculated at the HF/6-31G(d) level of theory within the G3 thermochemical protocol. 
Equilibrium Constants and Rate Coefficient Calculations. Canonical transition state rate theory and statistical thermodynamics ${ }^{44-46}$ were employed to calculate the high-pressure limiting rate coefficients $\left(k_{\infty}(T)\right)$ and equilibrium constants $(K(T))$ using Eq. 1 and Eq. 2, respectively:

$$
\begin{gathered}
k_{\infty}(T)=n \kappa \frac{k_{B} T}{h} \frac{\left(Q_{i}^{\ddagger} / V\right)}{\prod_{\text {reactants }}\left(Q_{i} / V\right)} \exp \left(-\frac{\Delta^{\ddagger} E_{0}}{k_{B} T}\right) \\
E q .1 \\
K(T)=\frac{\prod_{\text {products }}\left(Q_{i} / V\right)}{\prod_{\text {reactants }}\left(Q_{i} / V\right)} \exp \left(-\frac{\Delta H_{r x n, 0 K}^{0}}{k_{B} T}\right)
\end{gathered}
$$

where, $Q_{i}$ denotes the molecular partition functions for the species $i$ and $\neq$ identifies a transition state; $E_{0}$ and $\Delta H^{0}$ are the threshold energy (including zero point vibrational energy) and enthalpy of reaction at $0 \mathrm{~K}$, respectively; $V$ is the volume; $k \mathrm{~B}$ is Boltzmann's constant; $h$ is Planck's constant and $R$ is the universal gas constant. Based on the molecular parameters obtained from quantum chemical calculations, rotational and vibrational partition functions were calculated using the rigid rotor-harmonic oscillator approximation except for low lying torsional modes. The electronic partition functions were set equal to 2 for the transition state and 4 for the $\mathrm{Br}$ atom arising from electron-spin splitting of $3685 \mathrm{~cm}^{-1}$. Due to spin-orbit coupling, the two quantum states of the $\mathrm{Br}$ atom ([Ar] $\left.3 \mathrm{~d}^{10} 4 \mathrm{~s}^{2} 4 \mathrm{p}^{5}\right)$, namely ${ }^{2} \mathrm{P}_{3 / 2}$ and ${ }^{2} \mathrm{P}_{1 / 2}$ with quantum weights of 4 and 2 , respectively, differ by an energy of $3685 \mathrm{~cm}^{-1} .{ }^{47}$ In Eq. (1), the reaction path degeneracy $(n)$ is given by $n=$ $\frac{\mathrm{m}_{\mathrm{TS}} \times \sigma_{\mathrm{reactant}}}{\mathrm{m}_{\text {reactant }} \times \sigma_{\mathrm{TS}}}$. Here, $\sigma$ and $m$ are the external symmetry numbers and the number of optical isomers of the reactant and the transition states, respectively. $\kappa$ is the transmission coefficient which takes into account tunneling effects through an asymmetric Eckart barrier. The temperature-dependent rate coefficients and equilibrium constants were computed using the THERMO tool of the MultiWell Master Equation Program Suite. ${ }^{48}$ 


\section{Results and Discussion}

\section{Potential Energy Surface and Thermodynamic Properties.}

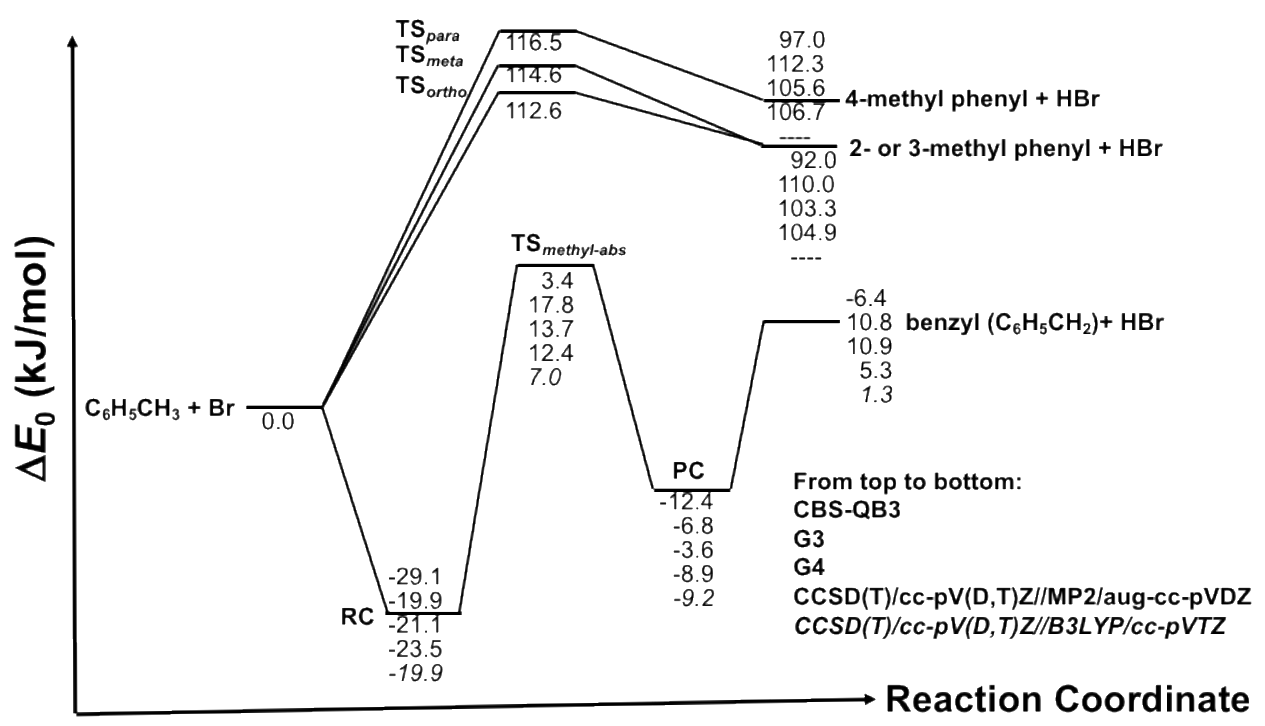

Figure 2: Zero-point energy corrected potential energy surface for the toluene $+\mathrm{Br}$ reaction. The relative energies are computed at the CBS-QB3, G3, G4, CCSD(T)/cc-pV(D,T)Z//MP2/aug-ccpVDZ CCSD(T)/cc-pV(D,T)Z//B3LYP/cc-pVTZ levels of theory from top to bottom, respectively. The relative energies of $\mathrm{TS}_{\text {para }}, \mathrm{TS}_{\text {meta }}$ and $\mathrm{TS}$ ortho are computed at $\mathrm{G} 3$ level of theory (see text for explanation).

Unlike $\mathrm{Cl}$ atoms, $\mathrm{Br}$ atoms display a substantial variation in reactivity with the nature of the VOCs. ${ }^{12-14}$ Giri et al. ${ }^{12}$ have shown that the reaction kinetics of $\mathrm{Br}$ atoms with VOCs can be difficult to predict as their chemistry is quite complex and often takes place via several elementary steps. For the reactions of Br with VOCs, a large variation in the enthalpy of activation and entropy of activation is observed (see Giri et al. ${ }^{15}$ ). Such variation mainly stems from the structural differences in the transition states of the reactions of Br atoms with structurally similar VOCs. In view of the complexity of the reaction, the potential energy surface (PES) of the $\mathrm{Br}$ atom reaction with toluene $\left(\mathrm{C}_{6} \mathrm{H}_{5} \mathrm{CH}_{3}\right)$ was mapped out at various levels of theory. Figure 2 depicts the computed 
PES showing various reaction pathways of the $\mathrm{Br}+\mathrm{C}_{6} \mathrm{H}_{5} \mathrm{CH}_{3}$ reaction. As can be seen, there are several plausible pathways for the reaction of $\mathrm{Br}$ atoms with $\mathrm{C}_{6} \mathrm{H}_{5} \mathrm{CH}_{3}$. The most energetically feasible pathway occurs via complex formation at both the entrance and exit channels to eventually release $\mathrm{HBr}$ in an overall endothermic process (except at the CBS-QB3 level of theory where $\left.\Delta H^{\circ}{ }_{\text {rxn }, 0 \mathrm{~K}}=-6.4 \mathrm{~kJ} / \mathrm{mol}\right)$. This is similar to the behavior seen in the reactions of $\mathrm{Br}$ with cyclic ethers ${ }^{12-14}$ and with $\mathrm{CH}_{3} \mathrm{OH}^{49}$.

At the entrance channel, the $\mathrm{Br}$ atom forms a pre-reaction complex (RC) with $\mathrm{C}_{6} \mathrm{H}_{5} \mathrm{CH}_{3}$ via a barrierless process. The relative stability of RC depends upon the level of theory used. CBS-QB3 predicts the highest stability of RC (29 kJ/mol lower than the reactants). However, CBS-QB3 does not seem to perform well for a reliable energetic picture of the present system. The CBS-QB3 level of theory predicts the reaction of $\mathrm{Br}$ atoms with toluene to be exothermic $\left(\Delta H^{\circ}{ }_{\mathrm{rxn}}, 0 \mathrm{~K}=-6.4 \mathrm{~kJ} / \mathrm{mol}\right)$. According to the highly accurate Ruscic's Active Thermochemical Tables $(\mathrm{AcTc})^{50}$, this reaction, in fact, is an endothermic reaction $\left[\Delta H^{\circ}{ }_{\mathrm{rxn}}, 0 \mathrm{~K}=(10.74 \pm 0.53) \mathrm{kJ} / \mathrm{mol}\right]$. The relative energies computed at CBS-QB3 level of theory show large deviations as compared to other levels of theory (see Figure 2). Overall, CBS-QB3 performs poorly. Therefore, subsequent discussion does not include CBS-QB3 energetics. The stability of the pre-reaction complex is found to be $(21.1 \pm 1.7)$ $\mathrm{kJ} / \mathrm{mol}$ relative to the reactants where the quoted uncertainty is one standard deviation. Similar stability of the pre-reaction complexes was observed for $\mathrm{Br}$ atom reactions with ethers. ${ }^{12-14}$ As we will justify later, the relative stability of the pre-reaciton complex does not alter the kinetics of the toluene $+\mathrm{Br}$ reaction. For reliable kinetics, the relative position of the transition state $\left(\mathrm{TS}_{\text {methyl-abs }}\right)$ is the most crucial. 
The reaction complex (RC) undergoes rearrangement via $\mathrm{TS}_{\text {methyl-abs }}$ to form a post reaction complex (PC) which eventually liberates $\mathrm{HBr}$ to produce a benzyl radical $\left(\mathrm{C}_{6} \mathrm{H}_{5} \mathrm{CH}_{2}\right)$. Unfortunately, the predicted barrier heights $\left(\Delta \mathrm{E}_{0}\right)$ of $\mathrm{TS}_{\text {methyl-abs }}$ show a strong dependence on the quantum method used. For example, G3 predicts the largest barrier height of $17.8 \mathrm{~kJ} / \mathrm{mol}$, whereas it is $7.0 \mathrm{~kJ} / \mathrm{mol}$ at the $\operatorname{CCSD}(\mathrm{T}) / \mathrm{cc}-\mathrm{pV}(\mathrm{D}, \mathrm{T}) / / \mathrm{B} 3 \mathrm{LYP} / \mathrm{cc}-\mathrm{pVTZ}$ level of theory. The predicted barrier heights from these two ab initio methods differ by $10.8 \mathrm{~kJ} / \mathrm{mol}$. In addition, the overall endothermicity of the reaction differs by $\sim 9.5 \mathrm{~kJ} / \mathrm{mol}$. We assess the source of discrepancy by looking into the extent of spin contamination in the unrestricted version of the quantum method used here. Severe spin contamination may lead to poor geometry, anomalous vibrational frequencies and high reaction barriers. ${ }^{51} \mathrm{G} 3$ appears to have suffered from spin contamination as the expected value of spin $\left(\left\langle\mathrm{S}^{2}\right\rangle=1.156\right)$ is still high after the spin annihilation steps for $\mathrm{TS}_{\text {methyl- }}$ abs. Note that G3 does geometry optimization and frequency calculations at the HF/6-31G(d) level of theory, then employs the MP2(full)//6-31G(d) level of theory to reoptimize the structure before embarking on the single point calculations. Therefore, MP2 optimized geometries may have been affected by spin contamination from higher spin states. An effective way of eliminating spincontamination is through the use of density functional theory (DFT). The DFT densities and energies are less affected by spin contamination than those of the corresponding unrestricted Hartee-Fock quantities. ${ }^{52-54}$ Note that G4 optimizes geometry at B3LYP/6-31G(2df,p), a hybrid DFT with 20\% HF exchange, before several single-point energy calculations are carried out. The $\left\langle\mathrm{S}^{2}\right\rangle$ values were found to be 0.7503 and 0.7507 for TS $\mathrm{T}_{\text {methyl-abs }}$ and $\mathrm{C}_{6} \mathrm{H}_{4} \mathrm{CH}_{2}$, respectively. This indicates that the G4 method exhibits negligible spin contamination as expected. 
Benchmarking against the most accurate ATcT database, G4 performs the best among the quantum methods used. For example, G4 predicts the endothermicity of the reaction (toluene $+\mathrm{Br} \rightarrow$ benzyl $+\mathrm{HBr}$ ) to be $10.9 \mathrm{~kJ} / \mathrm{mol}$ at $0 \mathrm{~K}$ which excellently agrees with that from ATcT $\left[\boldsymbol{\Delta}_{\mathbf{r n x}} \mathbf{H}_{\mathbf{0}} \mathrm{K}=\right.$ $(10.74 \pm 0.53) \mathrm{kJ} / \mathrm{mol}]$. The G4 enthalpy of formation of toluene and the benzyl radical at $0 \mathrm{~K}$, using the atomization scheme, yields $\Delta_{\mathrm{f}, 0 \mathrm{~K}} H^{0}=73.7 \mathrm{~kJ} / \mathrm{mol}$ and $228.8 \mathrm{~kJ} / \mathrm{mol}$, respectively. As can be seen in Table 2, these values agree excellently with ATcT values of $\Delta_{\mathrm{f}, 0 \mathrm{~K}} H^{0}=73.29 \pm 0.34 \mathrm{~kJ} / \mathrm{mol}$ for toluene and $229.9 \pm 0.6 \mathrm{~kJ} / \mathrm{mol}$ for the benzyl radical. Moreover, the G4 value of $\Delta H^{\circ}{ }_{\mathrm{f}, 0 \mathrm{~K}}$ for the benzyl radical agrees excellently with that of Hippler et al. ${ }^{55}\left[\Delta H^{\circ}\right.$, o K (benzyl) $]=(229.0 \pm 4.0)$ $\mathrm{kJ} / \mathrm{mol}]$ and Luo et al. $^{56}\left[\Delta H^{\circ}{ }_{\mathrm{f}, 0 \mathrm{~K}}(\right.$ benzyl $\left.\left.)\right]=(226.6 \pm 1.7) \mathrm{kJ} / \mathrm{mol}\right]$. Table 2 lists the standard enthalpy of formation of the product radicals of the toluene $+\mathrm{Br}$ reaction obtained by using atomization and isodesmic reaction schemes.

As seen in Table 2, the combination of the trio methods (G4/G3/CBS-APNO) yields $\Delta H^{\circ}$, $0 \mathrm{~K}$ $($ benzyl $)=(227.7 \pm 5.3) \mathrm{kJ} / \mathrm{mol}$ which compares excellently with the literature data and also with that obtained from the isodesmic reaction schemes. Despite the spin contamination issue discussed earlier, the G3 values for the formation enthalpy agree nicely with those of the isodesmic schemes, the mean of the G4/G3/CBS-APNO trio, and ATcT for the benzyl radical, within the chemical accuracy of these composite methods. ${ }^{57,58}$ Moreover, the G3 value of $10.8 \mathrm{~kJ} /$ mole for the enthalpy of reaction matches excellently with the ATcT value of $\Delta_{\mathbf{r n x}} \mathbf{H}_{\mathbf{0}}$ K $[(10.74 \pm 0.53) \mathrm{kJ} / \mathrm{mol}]$. This indicates that G3 data are not too severly affected by spin contamination. Therefore, there is no need to exclude the G3 data when evaluating the thermochemical quantities and kinetic data. With an adjustment of $<4 \mathrm{~kJ} / \mathrm{mol}$ in the barrier height, all the methods employed here performed well by capturing the experimental kinetic data satisfactorily as discussed below. 
Table 2: Comparison of the computed values for the standard enthalpy of formation of product radicals using atomization scheme and isodesmic reactions. Our values of the formation enthalpy of the benzyl radical is compared with the available data from the highly accurate ATcT database. The units are in $\mathrm{kJ} / \mathrm{mol}$.

\begin{tabular}{|c|c|c|c|c|c|c|c|c|c|c|c|c|}
\hline & \multicolumn{2}{|c|}{ G4 } & \multicolumn{2}{|c|}{ G3 } & \multicolumn{2}{|c|}{ CBS-APNO } & \multicolumn{2}{|c|}{$\operatorname{Mean}( \pm 1 \sigma)$} & \multicolumn{2}{|c|}{ Isodesmic } & \multicolumn{2}{|c|}{ ATcT } \\
\hline Species & $\Delta_{\mathrm{f}} \mathbf{H}_{0}$ & $\Delta_{\mathrm{f}} \mathbf{H}_{298}$ & $\Delta_{\mathrm{f}} \mathbf{H}_{0}$ & $\Delta_{\mathrm{f}} \mathbf{H}_{298}$ & $\Delta_{\mathrm{f}} \mathbf{H}_{0}$ & $\Delta_{\mathrm{f}} \mathrm{H}_{298}$ & $\Delta_{\mathrm{f}} \mathbf{H}_{0}$ & $\Delta_{\mathrm{f}} \mathbf{H}_{298}$ & $\Delta_{\mathrm{f}} \mathbf{H}_{0}$ & $\Delta_{\mathrm{f}} \mathbf{H}_{298}$ & $\Delta_{\mathrm{f}} \mathbf{H}_{0}$ & $\Delta_{\mathrm{f}} \mathbf{H}_{298}$ \\
\hline benzyl & 228.8 & 209.4 & 232.4 & 213.9 & 221.9 & 202.9 & $227.7 \pm 5.3$ & $212.3 \pm 5.5$ & $229.2 \pm 0.4$ & $209.2 \pm 0.4$ & $229.9 \pm 0.6$ & $211.1 \pm 0.6$ \\
\hline $\begin{array}{l}\text { 2- or 3- } \\
\text { methyl- } \\
\text { phenyl }\end{array}$ & 321.2 & 303.2 & 331.7 & 314.5 & 322.7 & 305.1 & $325.2 \pm 5.7$ & $303.2 \pm 6.0$ & $323.2 \pm 0.4$ & $304.3 \pm 0.4$ & --- & --- \\
\hline $\begin{array}{l}\text { 4-methyl- } \\
\text { phenyl }\end{array}$ & 323.5 & 305.5 & 333.9 & 316.8 & 325.0 & 307.4 & $327.5 \pm 5.6$ & $305.5 \pm 6.0$ & $325.5 \pm 0.4$ & $306.7 \pm 0.4$ & --- & --- \\
\hline
\end{tabular}

The MP2/aug-cc-pVDZ optimized geometry of the TS methyl-abs reveals that the formation of the transition state occurs too early in the reaction. MP2/aug-cc-pVDZ predicts the breaking of $\mathrm{C} 12 \ldots \mathrm{H} 13$ bond distance to be $\sim 1.43 \AA$ whereas it is at least $1.500 \AA$ at other levels of theory (see Table 1). Furthermore, the incoming $\mathrm{Br}$ atom is found to be somewhat farther from the hydrogen atom being abstracted at the MP2/aug-cc-pVDZ level of theory. For example, the new H13....Br bond is $1.581 \AA$ and $\sim 1.55 \AA$ at the MP2/aug-cc-pVDZ and other levels of theory employed here, respectively. In all cases, the bond angle, $\delta(\mathrm{C} 12 \ldots \mathrm{H} 13 \ldots \mathrm{Br})$, comes close to $175^{\circ}$. Therefore, the TS methyl-abs optimized at the MP2/aug-cc-pVDZ level of theory reveals an early transition state having a character more like that of the reactants. As seen in Figure 2, TS methyl-abs is the bottleneck of the overall process of hydrogen abstraction from the methyl group of toluene which takes place via a $\mathrm{Br}$ atom addition and $\mathrm{HBr}$ elimination mechanism in an overall endothermic process. For the hydrogen abstraction reaction at the methyl site, the reaction sequence $\left(\mathrm{R}_{1 \mathrm{a}}-\mathrm{R}_{1 \mathrm{c}}\right)$ can be written as:
$\mathrm{C}_{6} \mathrm{H}_{5} \mathrm{CH}_{3}+\mathrm{Br} \leftrightharpoons \mathrm{RC}\left(\mathrm{C}_{6} \mathrm{H}_{5} \mathrm{CH}_{3} \ldots \mathrm{Br}\right)$
( $\left.\mathrm{R}_{1 \mathrm{a}}, \mathrm{R}_{-1 \mathrm{a}}\right)$
$\mathrm{RC} \rightarrow \mathrm{PC}\left(\mathrm{C}_{6} \mathrm{H}_{5} \mathrm{CH}_{2} \ldots . \mathrm{H}-\mathrm{Br}\right)$
$\left(\mathrm{R}_{1 b}\right)$
$\mathrm{PC} \rightarrow \mathrm{C}_{6} \mathrm{H}_{5} \dot{\mathrm{C}} \mathrm{H}_{2}+\mathrm{HBr}$
$\left(\mathrm{R}_{1 \mathrm{c}}\right)$ 
One can argue that $\mathrm{PC}$, instead of liberating $\mathrm{HBr}$ (reaction $\mathrm{R} 1 \mathrm{c}$ ), may undergo intramolecular rearrangement forming various isomers. One can further hypothesize that if these isomers land into deeper wells than PC, they may be stabilized under high pressure. In such a case, R 1 c would not be the only outlet of the reaction sequence $\left(\mathrm{R}_{1 \mathrm{a}}-\mathrm{R}_{1 \mathrm{c}}\right)$. Intuitively, one can think of eight possible isomers after such an intramolecular rearrangement occurs. The formation of these isomers involves migration of $\mathrm{HBr}$ on the benzyl radical moiety via the reaction pathways $\left(\mathrm{R}_{1 \mathrm{~d}}-\mathrm{R}_{1 \mathrm{j}}\right)$. To assess the kinetic relevance of these reaction pathways, the structures of the isomers of PC were optimized at G3 level of theory. Here, only seven of the reaction pathways were found as the local minimum for 4-bromo-4-methylcyclohexa-2,5-dien-1-yl radical does not exist. Structures of the species are provided in Figure S1 of the Supplementary Material. For the seven pathways, the G3 standard enthalpies of reaction at $0 \mathrm{~K}$ are provided below:

$$
\begin{aligned}
& \mathrm{PC} \rightarrow \text { (6-bromocyclohexa-2,4-dien-1-yl)methyl } \quad\left(\mathrm{R}_{1 \mathrm{~d}}\right) \\
& \Delta H^{\circ}{ }_{\mathrm{rxn}, 0 \mathrm{~K}}=36.3 \mathrm{~kJ} / \mathrm{mol} \\
& \rightarrow \text { (6-bromocyclohexa-1,3-dien-1-yl)methyl } \quad\left(\mathrm{R}_{1 \mathrm{e}}\right) \\
& \Delta H^{\circ}{ }_{\mathrm{rxn}, 0 \mathrm{~K}}=41.9 \mathrm{~kJ} / \mathrm{mol} \\
& \left.\rightarrow \text { 4-(bromomethyl)cyclohexa-2,5-dien-1-yl } \quad \text { ( } \mathrm{R}_{1 \mathrm{f}}\right) \\
& \Delta H_{\mathrm{rxn}, 0 \mathrm{~K}}^{\circ}=42.7 \mathrm{~kJ} / \mathrm{mol} \\
& \rightarrow \text { (5-bromocyclohexa-1,3-dien-1-yl)methyl } \quad\left(\mathrm{R}_{1 \mathrm{~g}}\right) \\
& \Delta H^{\circ}{ }_{\text {rxn, } 0 \mathrm{~K}}=62.6 \mathrm{~kJ} / \mathrm{mol} \\
& \rightarrow \text { (4-bromocyclohexa-1,3-dien-1-yl)methyl } \quad\left(\mathrm{R}_{1 \mathrm{~h}}\right) \\
& \Delta H^{\circ}{ }_{\text {rxn, } 0 \mathrm{~K}}=68.2 \mathrm{~kJ} / \mathrm{mol} \\
& \rightarrow \text { (1-bromocyclohexa-2,4-dien-1-yl)methyl } \quad\left(\mathrm{R}_{1 i}\right) \\
& \Delta H_{\mathrm{rxn}, 0 \mathrm{~K}}^{\circ}=115.7 \mathrm{~kJ} / \mathrm{mol}
\end{aligned}
$$




$$
\begin{gathered}
\rightarrow \text { (6-bromocyclohexa-2,4-dien-1-yl)methyl } \quad\left(\mathrm{R}_{1 \mathrm{j}}\right) \\
\Delta H^{\circ}{ }_{\mathrm{rxn}, 0 \mathrm{~K}}=135.8 \mathrm{~kJ} / \mathrm{mol}
\end{gathered}
$$

Among these channels, even the lowest lying endothermic reaction $\left(\mathrm{R}_{1 \mathrm{~d}}\right)$ is significantly more endothermic than $\mathrm{R}_{1 \mathrm{c}}\left[\Delta H_{\mathrm{rxn}}^{\circ}, 0 \mathrm{~K}(\mathrm{PC} \rightarrow \mathrm{Benzyl}+\mathrm{HBr})<17.6 \mathrm{~kJ} / \mathrm{mol}\right]$. Moreover, one can envision that these reactions $\left(\mathrm{R}_{1 \mathrm{~d}}-\mathrm{R}_{1 \mathrm{j}}\right)$ require substantial intramolecular rearrangement and occur via energetically high-lying tight transition states. Therefore, these reactions are expected to be kinetically irrelevant. Additionally, $\mathrm{PC}$ occupies a shallower well than $\mathrm{RC}$, and $\mathrm{R}_{1 \mathrm{c}}$ being also a barrierless processs, PC will have a shorter life-time than RC. The estimated life-time of RC is in the order of picoseconds (see discussion below). For these reasons, reactions $R_{1 d}-R_{1 j}$ originating from the PC well can be safely be ruled out.

A hydrogen abstraction reaction may also take place at ortho-, meta- and para- ring hydrogen atoms of toluene, reactions $\mathrm{R}_{2}-\mathrm{R}_{4}$. These reactions are found to be highly endothermic $\left(\Delta H^{\circ}{ }_{\text {rxn, }} 0 \mathrm{~K}\right.$ $>107 \mathrm{~kJ} / \mathrm{mol})$. The standard enthalpies of reaction $\left(\Delta H_{\mathrm{rxn}}^{\circ}, 0 \mathrm{~K}\right)$ given below are the averaged values obtained from the G3, G4 and CCSD(T)/cc-pV(D,T)// MP2/aug-cc-pVDZ levels of theory. $\mathrm{C}_{6} \mathrm{H}_{5} \mathrm{CH}_{3}+\mathrm{Br} \rightarrow$ 2-methyl phenyl $\left(\dot{\mathrm{C}}_{6} \mathrm{H}_{4} \mathrm{CH}_{3}\right)+\mathrm{HBr}$

$$
\begin{array}{r}
\Delta H^{\circ}{ }_{\text {rxn, } 0 \mathrm{~K}}=(107.1 \pm 3.4) \mathrm{kJ} / \mathrm{mol} \\
\rightarrow \text { 3-methyl phenyl }\left(\dot{\mathrm{C}}_{6} \mathrm{H}_{4} \mathrm{CH}_{3}\right)+\mathrm{HBr} \\
\Delta H^{\circ}{ }_{\mathrm{rxn}, 0 \mathrm{~K}}=(107.1 \pm 3.4) \mathrm{kJ} / \mathrm{mol} \\
\rightarrow \text { 4-methyl phenyl }\left(\dot{\mathrm{C}}_{6} \mathrm{H}_{4} \mathrm{CH}_{3}\right)+\mathrm{HBr} \\
\Delta H^{\circ}{ }_{\mathrm{rxn}, 0 \mathrm{~K}}=(109.2 \pm 3.4) \mathrm{kJ} / \mathrm{mol}
\end{array}
$$

The transition states corresponding to the ring hydrogen abstraction can only be located at the MP2 level of theory within the G3 thermochemical protocol whereas the B3LYP level of theory fails 
for all the basis sets studied here. Figure 1 shows the MP2(full)/6-31G(d) structures along with the relevant geometrical parameters of the transition states that are labeled as $\mathrm{TS}_{\text {ortho }}, \mathrm{TS}_{\text {meta }}, \mathrm{TS}_{\text {para }}$ to indicate the type of ring hydrogen atom being abstracted. The reaction routes via these transition states seem highly unlikely as the lowest lying transition state $\left(\mathrm{TS}_{\text {ortho }}\right.$ ) is $112.6 \mathrm{~kJ} / \mathrm{mol}$ higher in energy than the reactants (see Figure 2). As stated, other levels of theory employed here could not locate the transition states corresponding to the ring hydrogen abstraction. It may be possible that the process of new $\mathrm{H}$....Br bond formation and $\mathrm{C}$....H bond breaking is happening synchronously (SN2 reaction) in a seemingly barrierless reaction. In a similar study of the $\mathrm{Cl}$ atom reaction with benzene or toluene, the authors ${ }^{59}$ could not locate the transition state for the ring hydrogen abstraction. As a result, they concluded that the ring hydrogen abstraction reactions are barrierless processes. Whether the reactions $\mathrm{R}_{2}-\mathrm{R}_{4}$ are barrierless or not, they seem highly unlikely to compete with the hydrogen abstraction reaction at the methyl site because $R_{2}-R_{4}$ are energetically very demanding channels.

Further explorations of the additional reaction pathways were carried out at the G3 level of theory only. These reaction pathways include the substitution of a ring hydrogen atom or methyl group of toluene by a $\mathrm{Br}$ atom (reactions $\mathrm{R}_{5}-\mathrm{R}_{8}$, not shown in Figure 2).

$$
\begin{aligned}
\mathrm{C}_{6} \mathrm{H}_{5} \mathrm{CH}_{3}+\mathrm{Br} & \rightarrow \mathrm{C}_{6} \mathrm{H}_{5} \mathrm{Br}+\dot{\mathrm{C}} \mathrm{H}_{3} & \left(\mathrm{R}_{5}\right) & \Delta H^{\circ}{ }_{\text {rxn }}, 0 \mathrm{~K}=74 \mathrm{~kJ} / \mathrm{mol} \\
& \rightarrow \text { 2-bromotoluene }\left(\mathrm{C}_{6} \mathrm{H}_{4} \mathrm{BrCH}_{3}\right)+\mathrm{H} & \left(\mathrm{R}_{6}\right) & \Delta H^{\circ}{ }_{\text {rxn, } 0 \mathrm{~K}}=113.2 \mathrm{~kJ} / \mathrm{mol} \\
& \rightarrow \text { 3-bromotoluene }\left(\mathrm{C}_{6} \mathrm{H}_{4} \mathrm{BrCH}_{3}\right)+\mathrm{H} & \left(\mathrm{R}_{7}\right) & \Delta H^{\circ}{ }_{\text {rxn, } 0 \mathrm{~K}}=115.1 \mathrm{~kJ} / \mathrm{mol} \\
& \rightarrow \text { 4-bromotoluene }\left(\mathrm{C}_{6} \mathrm{H}_{4} \mathrm{BrCH}_{3}\right)+\mathrm{H} & \left(\mathrm{R}_{8}\right) & \Delta H^{\circ}{ }_{\mathrm{rxn}, 0 \mathrm{~K}}=116.1 \mathrm{~kJ} / \mathrm{mol}
\end{aligned}
$$

The substitution of a methyl group by a $\mathrm{Br}$ atom (reaction $\mathrm{R}_{5}$ ) is endothermic by $74 \mathrm{~kJ} / \mathrm{mol}$ at $0 \mathrm{~K}$. The corresponding transition state $\left(\mathrm{TS}_{\text {methyl-subs, }}\right.$, see Figure 1) lies at an energy of $156.7 \mathrm{~kJ} / \mathrm{mol}$ 
higher than the reactants. Since the barrier height of $\mathrm{R}_{5}$ is very high, this channel is also expected to be kinetically irrelevant. For the reactions of ring hydrogen atom substitution $\left(\mathrm{R}_{6}-\mathrm{R}_{8}\right)$, the standard enthalpies of the reactions are found to be at least $113 \mathrm{~kJ} / \mathrm{mol}$, and their corresponding transition states are expected to lie even higher in energy according to the Bell-Evans-Polanyi principle. Therefore, one can speculate that these substitution reactions will also not have any kinetic significance.

Kinetic Analysis and Reaction Rate Coefficients. The discussion in the preceding section suggests that the reaction of $\mathrm{Br}$ atoms with toluene proceeds exclusively by hydrogen abstraction at the methyl site via the reaction sequence $\left(\mathrm{R}_{1 \mathrm{a}}-\mathrm{R}_{1 \mathrm{c}}\right)$ to yield $\mathrm{HBr}$ and a benzyl radical $\left(\mathrm{C}_{6} \mathrm{H}_{5} \mathrm{CH}_{2}\right)$. For further confirmation, the rate coefficients for the ring hydrogen abstraction at the orthoposition $\left(\mathrm{R}_{2}\right)$ were calculated using Eq. 1 . Note that the reaction is highly endothermic $\left[\Delta H^{\circ}{ }_{\text {rxn }}, 0 \mathrm{~K}\right.$ $=(107.1 \pm 3.4) \mathrm{kJ} / \mathrm{mol}]$ and proceeds via $\mathrm{TS}_{\text {ortho }}$ overcoming an energy barrier of $112.6 \mathrm{~kJ} / \mathrm{mol}$, obtained at the G3 level of theory. Even at $500 \mathrm{~K}$, the rate coefficient was found to be extremely small $\left(k_{2} \sim 10^{-24} \mathrm{~cm}^{3}\right.$ molecule $\mathrm{s}^{-1} \mathrm{~s}^{-1}$. Such a slow reaction can not be observed in experiments. This conclusion is in line with the experimental observation of Bierback et al. ${ }^{22}$. Their kinetic investigations for the reaction of $\mathrm{Br}$ atoms with benzene were unsuccessful. They observed no detectable decay of benzene which allowed them to estimate an upper limit of the rate coefficient $\left(k_{\text {Br+benzene }} \leq 5 \times 10^{-16} \mathrm{~cm}^{3}\right.$ molecule $\left.\mathrm{s}^{-1} \mathrm{~s}^{-1}\right)$. These findings allow us to rule out all other remaining reaction pathways $\left(\mathrm{R}_{3}-\mathrm{R}_{8}\right)$ because they are energetically even more demanding. For example, the methyl substitution reaction $\left(\mathrm{R}_{5}\right)$ via $\mathrm{TS}_{\text {methyl-subs }}$ has to overcome a barrier height of $156.7 \mathrm{~kJ} / \mathrm{mol}$, making this channel kinetically highly unfavorable. Hence, the reaction of $\mathrm{Br}$ atoms with toluene takes place solely via an addition-elimination mechanism (reaction sequence $\mathrm{R}_{1 \mathrm{a}}-\mathrm{R}_{1 \mathrm{c}}$ ). 
Our kinetic analysis now focuses on the reaction sequence $\left(\mathrm{R}_{1 \mathrm{a}}-\mathrm{R}_{1 \mathrm{c}}\right)$ where the formation of an addition complex ( $\mathrm{RC}$ ) constitutes the intial step of a multistep mechanism of the $\mathrm{Br}+$ toluene reaction. Reaction $\mathrm{R}_{1 \mathrm{~b}}$, which takes place via the tight transition state $\mathrm{TS}_{\text {methyl-abs, }}$, has the highest threshold energy along the path of the reaction sequence $\left(\mathrm{R}_{1 \mathrm{a}}-\mathrm{R}_{1 \mathrm{c}}\right)$. One can expect that $\mathrm{R}_{-1 \mathrm{a}}$ occurs much faster than $\mathrm{R}_{1 \mathrm{~b}}$ due to much higher entropy. This can be readily seen when one combines $k_{1 a}$ $\sim 10^{-10} \mathrm{~cm}^{3}$ molecule ${ }^{-1} \mathrm{~s}^{-1}$ (collision limit for barrierless process) with the equilibrium constant $K_{1 \mathrm{a}}$ $(300 \mathrm{~K}) \sim 10^{-21} \mathrm{~cm}^{3}$ molecule ${ }^{-1}$ to obtain $k-1 \mathrm{a} \sim 10^{11} \mathrm{~s}^{-1}$. This value of $k$-1a is several orders of magnitude higher than $k_{1 \mathrm{~b}} \sim 10^{7} \mathrm{~s}^{-1}$ at $300 \mathrm{~K} . K_{1 \mathrm{a}}$ and $k_{1 \mathrm{~b}}$ are calculated using the parameters from G4 and/or $\operatorname{CCSD}(\mathrm{T}) / \mathrm{cc}-\mathrm{pV}(\mathrm{D}, \mathrm{T}) / / \mathrm{MP} 2 /$ aug-cc-pVDZ (abbreviated as XPOL) levels of theory. Clearly, this is a pre-equilibrium case where the reactants and the pre-reaction complex (RC) equilibrate rapidly, and the equilibrium is virtually not affected by reaction $1 \mathrm{~b}$. Therefore, a preequilibrium arises between the reactants and the addition complex (RC). In this scenario, the overall rate coefficient $\left(k_{1, \text { ov. }}\right)$ for the $\mathrm{Br}+$ toluene reaction can be given, with a reasonable approximation, by Eq. 3

$$
\begin{gathered}
k_{1, o v .}(T)=\frac{k_{1 a}(T) \times k_{1 b}(T)}{k_{-1 a}(T)+k_{1 b}(T)} \cong \frac{k_{1 a}(T) \times k_{1 b}(T)}{k_{-1 a}(T)}=K_{1 a}(T) \times k_{1 b}(T) \\
E q .3
\end{gathered}
$$

By combining Eq. 1, Eq. 2 and Eq. 3, the overall rate coefficient ( $\left.k_{1, \mathrm{ov} .}\right)$ can be written as:

$$
k_{1, o v .}(T)=n \kappa \frac{k_{B} T}{h} \frac{\left(Q_{\mathrm{TS}_{\text {methyl-abs }}}^{\ddagger} / V\right)}{\left(Q_{\mathrm{Br}} / V\right)\left(Q_{\text {toluene }} / V\right)} \exp \left[-\frac{\left.\left\{E\left(\mathrm{TS}_{\text {methyl-abs }}\right)-[E(\mathrm{Br})+E \text { (toluene })\right]\right\}}{k_{B} T}\right]
$$

Interestingly, the addition complex (RC) does not appear in Eq. 4, as if the reaction was a singlestep and RC had no kinetic relevance. However, the role of RC is implicitly embodied in the 
quantum tunneling factor $(\kappa)$. Its role may be critical at low temperatures where quantum tunneling becomes important. As the quantum tunneling factor depends upon the height and curvature of the reactive potential energy surface, the exclusion of the addition complex in the kinetic analysis may cause underprediction of the tunneling corrections. Therefore, Eq. 3 has been employed for the kinetic analyses to appropriately assess the tunneling correction.

Using the energetics displayed in Figure 2 and the molecular parameters provided in the

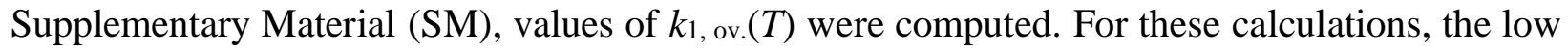
lying torsional modes for methyl rotors (e.g., $24 \mathrm{~cm}^{-1}$ for $\mathrm{C}_{6} \mathrm{H}_{5} \mathrm{CH}_{3}$ and $82 \mathrm{~cm}^{-1}$ for $\mathrm{RC}$ at G4 level of theory) were treated as free and 1-D hindered rotors, respectively. The barrier height of the internal rotation $\left(V_{0}\right)$ of $\mathrm{TS}_{\text {methyl-abs, }}$, corresponding to the harmonic frequency of $492 \mathrm{~cm}^{-1}$ after a relaxed potential energy scan at the B3LYP/6-31+G(D,P) level of theory, was found to be 50 $\mathrm{kJ} / \mathrm{mol}$ (see Figure S2 of Supplementary Material). This vibrational mode of $\mathrm{TS}_{\text {methyl-abs }}$ can, therefore, be safely treated as a harmonic oscillator because $V_{0} \gg k_{\mathrm{b}} T$. As can be seen in Figure 3, all the theoretical methods underpredict the experimental rate coefficients by at least a factor of 3 . Note that the overall rate coefficients, $k_{1}$, ov. $(T)$, calculated by using $\operatorname{CCSD}(\mathrm{T}) / \mathrm{cc}-\mathrm{pV}(\mathrm{D}, \mathrm{T}) / /$ B3LYP/cc-pVTZ parameters are not included in Figure 3. Using $\operatorname{CCSD}(\mathrm{T}) / \mathrm{cc}-\mathrm{pV}(\mathrm{D}, \mathrm{T}) / /$

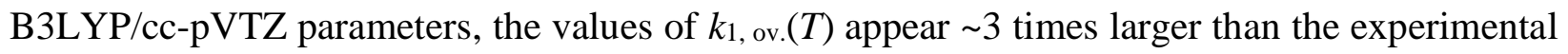

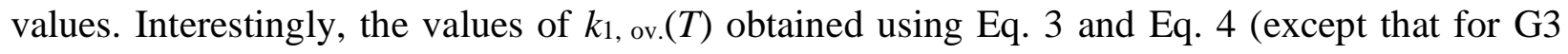
energetics) are identical revealing that the the pre-reaction complex is too short-lived a species to have any significant kinetic relevance for the toluene $+\mathrm{Br}$ chemical system. G3 parameters appear to overestimate the tunneling correction as discussed further below. Above $298 \mathrm{~K}$, the tunneling correction is unimportant. This conclusion may be extended to other aromatics $+\mathrm{Br}$ chemical 
systems as well. However, the hydrogen abstraction reaction of toluene by $\mathrm{OH}$ radicals can be quite different. Here, the pre-reaction complex was reported to play a crucial role in contributing to the tunneling correction. ${ }^{60}$

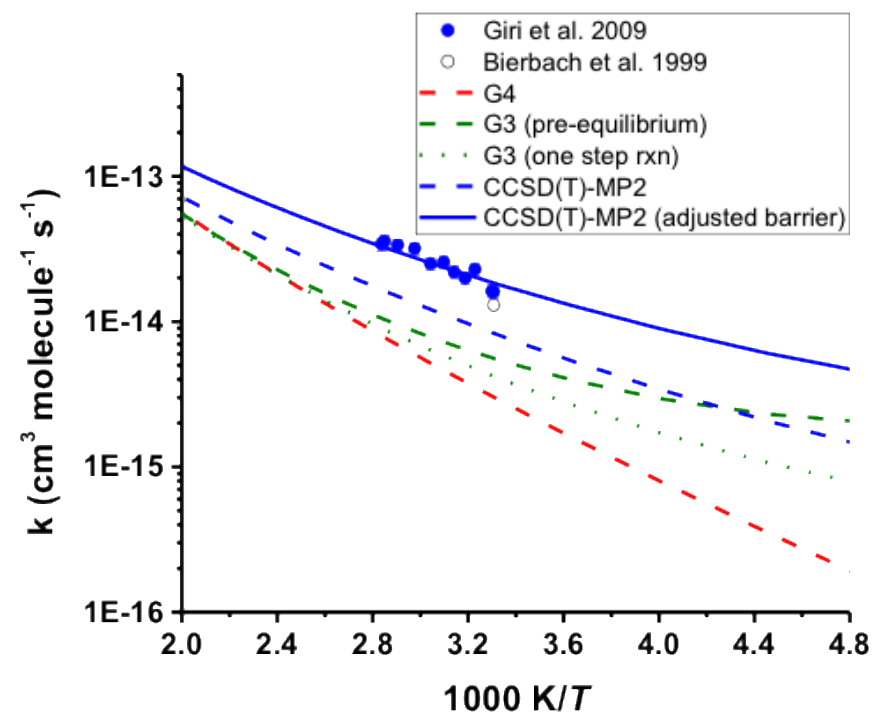

Figure 3: Temperature dependence of the rate coefficients for the reaction of $\mathrm{Br}$ atoms with toluene (reaction $\mathrm{R}_{1}$ ). Blue and open circles are the experimental data from Giri et al. ${ }^{15}$ and Bierbach et al. ${ }^{22}$, respectively. Lines represent the theoretical rate coefficients which are obtained using the parameters from the various quantum chemical methods as specified in the figure legend. The blue line is the result of Eq. 3 using $\operatorname{CCSD}(\mathrm{T}) / \mathrm{cc}-\mathrm{pV}(\mathrm{D}, \mathrm{T}) / / \mathrm{MP} 2 / \mathrm{aug}-\mathrm{cc}-\mathrm{pVDZ}$ parameters and lowering the barrier height of the TS $\mathrm{T}_{\text {methyl-abs }}$ by $2 \mathrm{~kJ} / \mathrm{mol}$.

The relative energy of the $\operatorname{TS}_{\text {methyl-abs }}\left(\Delta E_{0}=12.4 \mathrm{~kJ} / \mathrm{mol}\right)$ as predicted by $\mathrm{CCSD}(\mathrm{T}) / \mathrm{cc}$ $\mathrm{pV}(\mathrm{D}, \mathrm{T}) / / \mathrm{MP} 2 /$ aug-cc-pVDZ energetics comes close to capturing the experimental data. The barrier height at the $\operatorname{CCSD}(\mathrm{T}) / \mathrm{cc}-\mathrm{pV}(\mathrm{D}, \mathrm{T}) / / \mathrm{MP} 2 / \mathrm{aug}-\mathrm{cc}-\mathrm{pVDZ}$ level of theory is slightly lower than $\operatorname{CCSD}(\mathrm{T}) / \mathrm{cc}-\mathrm{pVTZ} / \mathrm{MP} 2 /$ aug-cc-pVDZ $\left(\Delta E_{0}=13.5 \mathrm{~kJ} / \mathrm{mol}\right)$. This implies that the extrapolation scheme using the cc-pVXZ $(X=3,4)$ basis sets may improve the energy by further lowering of the barrier height to match the experimental results. However, such calculations are computationally very demanding. Here, we refer to the computational work of Deb and Sarkar 
who assessed the performance of various quantum methods for understanding the oxidation behviour of the catechol $+\mathrm{O}_{3}$ reaction system. ${ }^{61}$ For such systems involving large aromatics, the authors reported that even the standard methods like $\operatorname{CSD}(\mathrm{T}) / \mathrm{CBS}$ may fail to accurately capture the experimental results, owing to large errors in the energetics. In the present case, a small correction of the barrier height from $\operatorname{CCSD}(\mathrm{T}) / \mathrm{cc}-\mathrm{pV}(\mathrm{D}, \mathrm{T}) / / \mathrm{MP} 2 / \mathrm{aug}-\mathrm{cc}-\mathrm{pVDZ}$ energetics, i.e., lowering of $\mathrm{TS}_{\text {methyl-abs }}$ by $2 \mathrm{~kJ} / \mathrm{mol}\left[E\left(\mathrm{TS}_{\text {methyl-abs }}\right)-E(\right.$ reactants $)=10.4 \mathrm{~kJ} / \mathrm{mol}$ at $\left.0 \mathrm{~K}\right]$, gave rate coefficients that are in excellent agreement with the experimental values (blue solid line in Figure 3). After the adjustment, the predicted rate coefficients compare nicely with the experimental data within the absolute average deviation of $7.7 \%$. Similarly, a lowering of $\sim 4 \mathrm{~kJ} / \mathrm{mol}$ for the barrier height is also needed for G4 and G3 levels of theory to match the experimental rate coefficients, and the barrier height needs to be raised by $\sim 3 \mathrm{~kJ} / \mathrm{mol}$ for the $\operatorname{CCSD}(\mathrm{T}) / \mathrm{cc}-\mathrm{pV}(\mathrm{D}, \mathrm{T}) / / \mathrm{B} 3 \mathrm{LYP} / \mathrm{cc}-$ pVTZ level of theory. Again, we note that these adjustments of the barrier heights are within the chemical accuracy of the ab initio methods used here. The adjusted barrier height of $10.4 \mathrm{~kJ} / \mathrm{mol}$ agrees closely with the enthalpy of activation $\left(\Delta H^{\ddagger}=10.8 \mathrm{~kJ} / \mathrm{mol}\right)$ reported by Giri et al. ${ }^{15}$ who calculated the thermodynamic parameters from their experimental kinetic data. The calculated values of the equilibrium constant $\left(K_{1 \mathrm{a}}\right)$, rate coefficients $\left(k_{1 \mathrm{~b}}\right)$ and overall rate coefficients $\left[k_{1, o v .}(T)=K_{1 a}(T) \times k_{1 b}(T)\right]$ are provided in

\section{Table 3.}

Table 3: Calculated rate coefficients for hydrogen abstraction from toluene by $\mathrm{Br}$ atoms based on the parameters calculated at the $\operatorname{CCSD}(\mathrm{T}) / \mathrm{cc}-\mathrm{pV}(\mathrm{D}, \mathrm{T}) \mathrm{Z} / / \mathrm{MP} 2 / \mathrm{aug}$-cc-pVDZ, G4 and G3 levels of theory with lowering the corresponding barrier heights by 2,4 and $4 \mathrm{~kJ} / \mathrm{mol}$, respectively. The $\mathrm{CCSD}(\mathrm{T}) / \mathrm{cc}-\mathrm{pV}(\mathrm{D}, \mathrm{T}) \mathrm{Z} / \mathrm{MP} 2 / \mathrm{aug}-\mathrm{cc}-\mathrm{pVDZ}$ level of theory is abbreviated as XPOL. The units are in $\mathrm{cm}^{3}$, molecule, $\mathrm{s}$.

\begin{tabular}{|r|l|l|l|l|l|l|l|l|l|l|l|}
\hline \multicolumn{4}{|c|}{ XPOL } & \multicolumn{3}{c|}{$\mathrm{G} 4$} & & \multicolumn{3}{c|}{$\mathrm{G} 3$} & \\
\hline$T(\mathrm{~K})$ & $K_{1 \mathrm{a}}$ & $k_{1 \mathrm{~b}}$ & $k_{1, \mathrm{ov} .}$ & $K_{1 \mathrm{a}}$ & $k_{1 \mathrm{~b}}$ & $k_{1, \mathrm{ov} .}$ & $\Gamma_{1} *$ & $K_{1 \mathrm{a}}$ & $k_{1 \mathrm{~b}}$ & $k_{1, \text { ov. }}$ & $\Gamma_{2} *$ \\
\hline 200 & $1.22 \mathrm{E}-19$ & $3.3 \mathrm{E}+04$ & $4.1 \mathrm{E}-15$ & $9.3 \mathrm{E}-20$ & $1.9 \mathrm{E}+04$ & $1.8 \mathrm{E}-15$ & 0.44 & $1.7 \mathrm{E}-18$ & $4.6 \mathrm{E}+03$ & $7.9 \mathrm{E}-15$ & 1.94 \\
\hline 225 & $2.70 \mathrm{E}-20$ & $2.3 \mathrm{E}+05$ & $6.1 \mathrm{E}-15$ & $2.5 \mathrm{E}-20$ & $1.4 \mathrm{E}+05$ & $3.6 \mathrm{E}-15$ & 0.59 & $5.3 \mathrm{E}-19$ & $1.7 \mathrm{E}+04$ & $8.8 \mathrm{E}-15$ & 1.44 \\
\hline
\end{tabular}




\begin{tabular}{|c|c|c|c|c|c|c|c|c|c|c|c|}
\hline 250 & $8.22 \mathrm{E}-21$ & $1.1 \mathrm{E}+06$ & $9.0 \mathrm{E}-15$ & $9.0 \mathrm{E}-21$ & $7.1 \mathrm{E}+05$ & $6.3 \mathrm{E}-15$ & 0.70 & $2.1 \mathrm{E}-19$ & $5.0 \mathrm{E}+04$ & $1.0 \mathrm{E}-14$ & 1.1 \\
\hline 275 & $3.15 \mathrm{E}-21$ & $4.1 \mathrm{E}+06$ & 1.3E-14 & 3.9E-21 & $2.7 \mathrm{E}+06$ & $1.0 \mathrm{E}-14$ & 0.78 & $1.0 \mathrm{E}-19$ & $1.3 \mathrm{E}+05$ & $1.3 \mathrm{E}-14$ & 1.01 \\
\hline 298 & $1.52 \mathrm{E}-21$ & $1.1 \mathrm{E}+07$ & $1.7 \mathrm{E}-14$ & $2.1 \mathrm{E}-21$ & $7.4 \mathrm{E}+06$ & $1.5 \mathrm{E}-14$ & 0.86 & $5.7 \mathrm{E}-20$ & $2.9 \mathrm{E}+05$ & $1.6 \mathrm{E}-14$ & 0.92 \\
\hline 300 & $1.43 \mathrm{E}-21$ & $1.2 \mathrm{E}+07$ & $1.8 \mathrm{E}-14$ & $2.0 \mathrm{E}-21$ & $8.1 \mathrm{E}+06$ & 1.6E-14 & 0.90 & $5.4 \mathrm{E}-20$ & $3.1 \mathrm{E}+05$ & $1.7 \mathrm{E}-14$ & 0.95 \\
\hline 325 & 7.42E-22 & $3.3 \mathrm{E}+07$ & 2.4E-14 & $1.1 \mathrm{E}-21$ & $2.1 \mathrm{E}+07$ & 2.4E-14 & 0.99 & 3.3E-20 & $6.6 \mathrm{E}+05$ & $2.1 \mathrm{E}-14$ & 0.87 \\
\hline 350 & $4.25 \mathrm{E}-22$ & $7.5 \mathrm{E}+07$ & 3.2E-14 & $7.0 \mathrm{E}-22$ & $4.8 \mathrm{E}+07$ & 3.3E-14 & 1.03 & $2.1 \mathrm{E}-20$ & $1.3 \mathrm{E}+06$ & $2.8 \mathrm{E}-14$ & 0.88 \\
\hline 375 & $2.64 \mathrm{E}-22$ & $1.6 \mathrm{E}+08$ & 4.1E-14 & 4.7E-22 & $9.8 \mathrm{E}+07$ & 4.6E-14 & 1.12 & $1.5 \mathrm{E}-20$ & $2.4 \mathrm{E}+06$ & 3.6E-14 & 0.87 \\
\hline 400 & $1.76 \mathrm{E}-22$ & $3.0 \mathrm{E}+08$ & 5.3E-14 & 3.3E-22 & $1.8 \mathrm{E}+08$ & $6.1 \mathrm{E}-14$ & 1.16 & 1.1E-20 & $4.2 \mathrm{E}+06$ & 4.6E-14 & 0.88 \\
\hline 425 & $1.23 \mathrm{E}-22$ & $5.3 \mathrm{E}+08$ & $6.5 \mathrm{E}-14$ & $2.4 \mathrm{E}-22$ & $3.3 \mathrm{E}+08$ & 7.9E-14 & 1.21 & 8.3E-21 & $7.0 \mathrm{E}+06$ & $5.8 \mathrm{E}-14$ & 0.89 \\
\hline 450 & 8.99E-23 & $8.9 \mathrm{E}+08$ & 8.0E-14 & $1.9 \mathrm{E}-22$ & $5.4 \mathrm{E}+08$ & $1.0 \mathrm{E}-13$ & 1.25 & -21 & $1.1 \mathrm{E}+07$ & 7.4E-14 & 0.92 \\
\hline 475 & $6.83 \mathrm{E}-23$ & $1.4 \mathrm{E}+09$ & $9.7 \mathrm{E}-14$ & $1.5 \mathrm{E}-22$ & $8.6 \mathrm{E}+08$ & -13 & 1.34 & $5.4 \mathrm{E}-21$ & $1.7 \mathrm{E}+07$ & $9.2 \mathrm{E}-14$ & 0.95 \\
\hline 500 & $5.35 \mathrm{E}-23$ & $2.2 \mathrm{E}+09$ & $1.2 \mathrm{E}-13$ & $1.2 \mathrm{E}-22$ & $1.3 \mathrm{E}+09$ & 1.6 & 1.37 & 4.5E-21 & $2.6 \mathrm{E}+07$ & $1.1 \mathrm{E}-13$ & 0.94 \\
\hline
\end{tabular}

$*^{*} \Gamma_{1}=k_{1, \text { ov. }}(\mathrm{G} 4) / k_{1, \text { ov. }}(\mathrm{XPOL})$ and $\left.\Gamma_{2}=k_{1, \mathrm{ov} .}(\mathrm{G} 3) / k_{1, \mathrm{ov} .} . \mathrm{XPOL}\right)$

As seen in Figure 3, the calculated values of $k_{1, o v}(T)$ using G3 unadjusted parameters, in contrast, show a strong curvature in the Arrhenius behavior highlighting the importance of quantum tunneling and hence the kinetic relevance of the pre-reaction complex. At $200 \mathrm{~K}$, the G3 calculated rate coefficient is $\sim 14.4$ times larger than that obtained from G4 or $\operatorname{CCSD}(\mathrm{T}) / \mathrm{cc}-$ $\mathrm{pV}(\mathrm{D}, \mathrm{T}) / / \mathrm{MP} 2 /$ aug-cc-pVDZ parameters, whereas the value of the G3 rate coefficient is roughly a factor of 2 larger than the G4 value at $300 \mathrm{~K}$. Additionally, inclusion of the pre-reaction (RC) complex, that is using Eq. 3, yielded G3 rate coefficients that are $\sim 3$ times larger than those obtained from a one-step reaction (Eq. 4) around 200 K. Note that these comparisons are for the rate coefficients obtained with the unadjusted barrier heights. The differences in the calculated values of the rate coefficients with the unadjusted barrier heights may indicate the importance of quantum tunneling at low temperatures. One can understand these differences by analyzing the parameters from various levels of theory. Rate coefficients with adjusted barriers heights are compared in

\section{Table 3.}


Geometry optimization at various levels of theory yields large variation in the imaginary frequency $\left(v^{\ddagger}\right)$. For example, G3 predicts quite a large value of $v^{\ddagger}\left(1579 \mathrm{~cm}^{-1}\right)$ for TS $\mathrm{T}_{m e t h y l-a b s}$ characterizing this transition state to be tight with a large curvature whereas the imaginary frequencies are 353 , 482, 843 and $527 \mathrm{~cm}^{-1}$ corresponding to the G4, CBS-QB3, CCSD(T)/cc-pV(D,T)//MP2/aug-ccpVDZ and $\operatorname{CCSD}(\mathrm{T}) / \mathrm{cc}-\mathrm{pV}(\mathrm{D}, \mathrm{T}) / \mathrm{B} 3 \mathrm{LYP} / \mathrm{cc}-\mathrm{pVTZ}$ levels of theory, respectively. If one incorporates G3 parameters to calculate the Eckart barrier width $(L)$, a rather small value of $0.125 \AA$ is obtained, whereas $L$ is predicted to be quite large at other levels of theory (e.g., 0.497 and 0.315 $\AA$ at the $\mathrm{G} 4$ and $\operatorname{CCSD}(\mathrm{T}) / \mathrm{cc}-\mathrm{pV}(\mathrm{D}, \mathrm{T}) / \mathrm{B} 3 \mathrm{LYP} / \mathrm{cc}-\mathrm{pVTZ}$ levels of theory, respectively). The Eckart barrier width $L$ is calculated using Eq. 5 and Eq. 6.

$$
\begin{gathered}
\frac{L}{2 \pi}=\sqrt{-\frac{2}{F^{\ddagger}}\left[\frac{1}{\sqrt{E_{f}}}+\frac{1}{\sqrt{E_{b}}}\right]^{-1}} \quad \text { Eq. } 5 \\
v^{\ddagger}=\frac{1}{2 \pi} \sqrt{-\frac{F^{\ddagger}}{\mu}} \quad \text { Eq. } 6
\end{gathered}
$$

Here, $E_{\mathrm{f}}$ and $E_{\mathrm{b}}$ are the forward and reverse barrier heights at $0 \mathrm{~K}$, respectively, $F^{\ddagger}$ is the second derivative of the potential energy function evaluated at its maximum (force constant), $v^{\ddagger}$ is the imaginary frequency of the transition state, and $\mu$ is the reduced mass of the tunneling moiety. Due to the small width of the Eckart barrier, the G3 parameters induce a large quantum tunneling correction. An adjustment to lower the $\mathrm{G} 3$ barrier height of $\mathrm{TS}_{\text {methyl-abs }}$ by $4 \mathrm{~kJ} / \mathrm{mol}$ yielded values of $k_{1, o v .}(T)$ that are close to, but show a different trend from, that observed in the experimental data. The temperature dependence of the predicted rate coefficients is severely curved. Unlike the rate coefficients obtained from the G4, $\operatorname{CCSD}(\mathrm{T}) / \mathrm{cc}-\mathrm{pV}(\mathrm{D}, \mathrm{T}) / / \mathrm{MP} 2 /$ aug-cc-pVDZ and $\operatorname{CCSD}(\mathrm{T}) / \mathrm{cc}-\mathrm{pV}(\mathrm{D}, \mathrm{T}) / / \mathrm{B} 3 \mathrm{LYP} / \mathrm{cc}-\mathrm{pVTZ}$ levels of theory, G3 values are found to be too high 
around $200 \mathrm{~K}$, and they are consistently lower than the experimental data for a given temperature. This observation leads us to conclude that the G3 parameters overestimate the quantum tunneling correction by incorrectly highlighting the significance of the pre-reaction complex for kinetic analysis of the toluene $+\mathrm{Br}$ reaction.

\section{Conclusions}

The kinetics of the reaction of $\mathrm{Br}$ atoms with toluene were investigated by employing statistical rate theory and quantum chemical calculations at different levels of theory. Several reaction pathways were found in the potential energy surface of the $\mathrm{Br}+$ toluene reaction. The following conclusions are drawn:

1. Only the hydrogen abstraction reaction by $\mathrm{Br}$ atoms at the methyl site of toluene is important. Like the $\mathrm{Br}+$ ethers reactions, this reaction proceeds via the formation of complexes at both the entrance and exit channels in an overall endothermic process. Other channels (e.g., ring hydrogen abstraction and Br-substitution reactions) are energetically very demanding, so these channels are kinetically irrelevant for the $\mathrm{Br}+$ toluene reaction.

2. The CBS-QB3 level of theory is not appropriate to quantitively describe the energetic picture of the toluene $+\mathrm{Br}$ reaction. This may be the case for other similar systems like the reactions of other aromatics with $\mathrm{Br}$. Within chemical accuracy, the energy profiles obtained at the G3 and G4 levels of theory are very comparable with that obtained from the CCSD(T)/CBS level of theory. The G3 and G4 values of the standard enthalpy of reaction agree excellently with that obtained from Ruscic's Active Thermochemical Tables. Combination of the G4/CBS-APNO/G3 trio methods yields formation enthalpies of the radicals that agree excellently with the ATcT database and the isodesmic reaction 
scheme. We conclude that the G3 and G4 composite methods may also provide a quantitative picture for the kinetics and thermochemistry of the reactions of $\mathrm{Br}$ atoms with aromatics.

3. Unlike other levels of theory used here, the G3 level of theory predicts quite a large value of the imaginary frequency. This led to a severe curvature in the Arrhenius behavior of the $\mathrm{Br}+$ toluene reaction revealing a large quantum tunneling correction at low temperatures. However, this is somewhat contrasting to the trend shown by the experimental data. Therefore, we conclude that the G3 parameters overpredict the quantum tunneling correction at low temperatures.

4. A small adjustment of $\sim 2 \mathrm{~kJ} / \mathrm{mol}$ in the barrier height of $\mathrm{TS}_{\text {methyl-abs }}$ obtained at the $\mathrm{CCSD}(\mathrm{T}) / \mathrm{cc}-\mathrm{pV}(\mathrm{D}, \mathrm{T}) / \mathrm{MP} 2 /$ aug-cc-pVDZ level of theory yielded rate coefficients that are in excellent agreement the experimental data. As for $\operatorname{CCSD}(\mathrm{T}) / \mathrm{cc}-\mathrm{pV}(\mathrm{D}, \mathrm{T}) / / \mathrm{B} 3 \mathrm{LYP} / \mathrm{cc}-$ pVTZ energetics, the barrier height needs to be raised by $3 \mathrm{~kJ} / \mathrm{mol}$ to match the experimental results. By lowering the barrier height by $\sim 4 \mathrm{~kJ} / \mathrm{mole}$, the $\mathrm{G} 4$ parameters yielded rate coefficients that also matched the experimental values excellently. With similar adjustment, the G3 rate coefficients also showed a nice agreement with experiment. However, the G3 values yielded a severely curved Arrhenius plot by overly correcting the quantum tunneling at the low temperature end.

5. The life-time of the pre-reaciton complex (RC) appears too short above room temperatures. Therefore, both the single-step and complex forming mechanisms yield identical rate coefficients. Albeit the $\mathrm{Br}+$ toluene reaction system would like a one-step process, the prereaction complex exists, and it may play a role at extremely cold temperatures. 


\section{Acknowledgements}

Research reported in this work was funded by King Abdullah University of Science and Technology (KAUST). This research was also supported by the European Union and the Hungarian State, co-financed by the European Regional Development Fund in the framework of the GINOP-2.3.4-15-2016-00004 project, aimed to promote cooperation between higher education and industry. 


\section{References}

1. Molina, M. J.; Rowland, F. S., Stratospheric sink for chlorofluoromethanes: chlorine atomcatalysed destruction of ozone. Nature 1974, 249 (5460), 810-812.

2. Finlayson-Pitts, B.; Livingston, F.; Berko, H., Ozone destruction and bromine photochemistry at ground level in the Arctic spring. Nature 1990, 343 (6259), 622-625.

3. Bottenheim, J. W.; Barrie, L. A.; Atlas, E.; Heidt, L. E.; Niki, H.; Rasmussen, R. A.; Shepson, P. B., Depletion of lower tropospheric ozone during Arctic spring: The polar sunrise experiment 1988. $J$. Geophys. Res. Atmos. 1990, 95 (D11), 18555-18568.

4. McGillen, M. R.; Carter, W. P. L.; Mellouki, A.; Orlando, J. J.; Picquet-Varrault, B.; Wallington, T. J., Database for the kinetics of the gas-phase atmospheric reactions of organic compounds. Earth Syst. Sci. Data Discuss. 2020, 2020, 1-24.

5. $\quad$ Manion, J.; Huie, R.; Levin, R.; Burgess Jr, D.; Orkin, V.; Tsang, W.; McGivern, W.; Hudgens, J.; Knyazev, V.; Atkinson, D., NIST Chemical Kinetics Database, NIST Standard Reference Database 17, Version 7.0 (Web Version), Release 1.6. 8, Data version 2015.09, National Institute of Standards and Technology, Gaithersburg, Maryland, 20899-8320. Web address: http://kinetics.nist.gov

6. Ammann, M.; Cox, R.; Crowley, J.; Jenkin, M.; Mellouki, A.; Rossi, M.; Troe, J.; Wallington, T.; Cox, B.; Atkinson, R., IUPAC Task Group on Atmospheric Chemical Kinetic Data Evaluation. 2016.

7. $\quad$ Atkinson, R.; Baulch, D.; Cox, R.; Crowley, J.; Hampson, R.; Hynes, R.; Jenkin, M.; Rossi, M.; Troe, J., Evaluated kinetic and photochemical data for atmospheric chemistry: Volume II gas phase reactions of organic species. Atmos. Chem. Phys. 2006, 6, 3625-4055.

8. Finlayson-Pitts, B. J., Multiphase chemistry in the troposphere: It all starts... and ends... with gases. Int. J. Chem. Kinet. 2019, 51 (10), 736-752.

9. Saiz-Lopez, A.; von Glasow, R., Reactive halogen chemistry in the troposphere. Chem. Soc. Rev. 2012, 41 (19), 6448-6472.

10. Atkinson, R.; Arey, J., Atmospheric Degradation of volatile organic compounds. Chem. Rev. 2003, 103 (12), 4605-4638.

11. Pitts, B. F.; Pitts, J. N., Chemistry of the upper and lower atmosphere: Theory, experiments and applications. Academic Press, New York, 2000.

12. Giri, B. R.; Lo, J. M.; Roscoe, J. M.; Alquaity, A. B.; Farooq, A., Theoretical study of the reaction kinetics of atomic bromine with tetrahydropyran. J. Phys. Chem. A 2015, 119 (6), 933-942.

13. Lo, J. M.; Marriott, R. A.; Giri, B. R.; Roscoe, J. M.; Klobukowski, M., A theoretical analysis of the kinetics of the reaction of atomic bromine with tetrahydrofuran. Can. J. Chem. 2010, 88 (11), 11361145 .

14. Giri, B. R.; Roscoe, J. M.; González-García, N.; Olzmann, M., Experimental and theoretical analysis of the kinetics of the reaction of atomic bromine with 1, 4-dioxane. J. Phys. Chem. A 2010, 114 (1), 291-298.

15. Giri, B. R.; Roscoe, J. M., Temperature dependence of the rate coefficients for the reactions of atomic bromine with toluene, tetrahydrofuran, and tetrahydropyran. J. Phys. Chem. A 2009, 113 (28), 80018010.

16. Anthony, L. M.; Roscoe, J. M., A kinetic analysis of the effect of $\mathrm{O}_{2}$ on the reactions of atomic bromine with some hydrocarbons and ethers. J. Phys. Chem. A 2004, 108 (37), 7535-7547.

17. Wheeler, M.; Mills, R.; Roscoe, J. M., Temperature dependence of the rate coefficients for the reactions of $\mathrm{Br}$ atoms with dimethyl ether and diethyl ether. J. Phys. Chem. A 2008, 112 (5), 858-865.

18. Giri, B. R.; Roscoe, J. M.; González-García, N.; Olzmann, M.; Lo, J. M.; Marriott, R. A., Experimental and theoretical investigation of the kinetics of the reaction of atomic chlorine with 1, 4dioxane. J. Phys. Chem. A 2011, 115 (20), 5105-5111.

19. Frazee, W. J.; Roscoe, J. M., Temperature dependence of the reactions of $\mathrm{Cl}$ with toluene and the xylenes. Int. J. Chem. Kinet. 2019, 51 (8), 579-589.

20. Wang, L.; Arey, J.; Atkinson, R., Reactions of chlorine atoms with a series of aromatic hydrocarbons. Environ. Sci. Technol. 2005, 39 (14), 5302-5310. 
21. Ezell, M. J.; Wang, W.; Ezell, A. A.; Soskin, G.; Finlayson-Pitts, B. J., Kinetics of reactions of chlorine atoms with a series of alkenes at $1 \mathrm{~atm}$ and $298 \mathrm{~K}$ : structure and reactivity. Phys. Chem. Chem. Phys. 2002, 4 (23), 5813-5820.

22. Bierbach, A.; Barnes, I.; Becker, K., Rate constants of the Br-initiated gas-phase oxidation of a

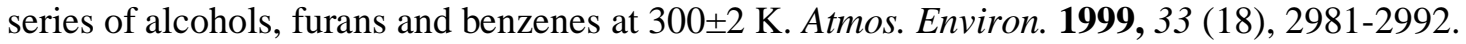

23. Møller, C.; Plesset, M. S., Note on an approximation treatment for many-electron systems. Phys. Rev. 1934, 46 (7), 618-622.

24. Becke, A. D., Density-functional thermochemistry. I. The effect of the exchange-only gradient correction. J. Chem. Phys. 1992, 96 (3), 2155-2160.

25. Becke, A. D., Density-functional thermochemistry. IV. A new dynamical correlation functional and implications for exact-exchange mixing. J. Chem. Phys. 1996, 104 (3), 1040-1046.

26. Becke, A. D., Density-functional thermochemistry. V. Systematic optimization of exchangecorrelation functionals. J. Chem. Phys. 1997, 107 (20), 8554-8560.

27. Wilson, A. K.; Woon, D. E.; Peterson, K. A.; Jr., T. H. D., Gaussian basis sets for use in correlated molecular calculations. IX. The atoms gallium through krypton. J. Chem. Phys. 1999, 110 (16), 7667-7676. 28. Dunning, T. H., Gaussian basis sets for use in correlated molecular calculations. I. The atoms boron through neon and hydrogen. J. Chem. Phys. 1989, 90 (2), 1007-1023.

29. Kendall, R. A.; Dunning, T. H.; Harrison, R. J., Electron affinities of the first-row atoms revisited. Systematic basis sets and wave functions. J. Chem. Phys. 1992, 96 (9), 6796.

30. Woon, D. E.; Dunning, T. H., Gaussian-Basis Sets for Use in Correlated Molecular Calculations .3. The Atoms Aluminum through Argon. J. Chem. Phys. 1993, 98 (2), 1358-1371.

31. Johnson, R. D., NIST computational chemistry comparison and benchmark database (CCCBDB). September 2015 ed.; Vol. NIST Standard Reference Database Number 101 Release 17b.

32. Scuseria, G. E.; Janssen, C. L.; Schaefer, H. F., An efficient reformulation of the closed-shell coupled cluster single and double excitation (CCSD) equations. J. Chem. Phys 1988, 89 (12), 7382.

33. Scuseria, G. E.; Schaefer, H. F., Is coupled cluster singles and doubles (CCSD) more computationally intensive than quadratic configuration interaction (QCISD)? J. Chem. Phys. 1989, 90 (7), 3700 .

34. Purvis, G. D.; Bartlett, R. J., A full coupled-cluster singles and doubles model: The inclusion of disconnected triples. J. Chem. Phys. 1982, 76 (4), 1910-1918.

35. Pople, J. A.; Head-Gordon, M.; Raghavachari, K., Quadratic configuration interaction. A general technique for determining electron correlation energies. J. Chem. Phys. 1987, 87 (10), 5968-5975.

36. Martin, J. M., Ab initio total atomization energies of small molecules - towards the basis set limit. Chem. Phys. Lett. 1996, 259 (5-6), 669-678.

37. Feller, D.; Dixon, D. A., Extended benchmark studies of coupled cluster theory through triple excitations. J. Chem. Phys. 2001, 115 (8), 3484-3496.

38. Lee, T. J.; Taylor, P. R., A diagnostic for determining the quality of single-reference electron correlation methods. Int. J. Quantum. Chem. 1989, 23, 199-207.

39. Klippenstein, S. J.; Harding, L. B., Kinetics of the H+ NCO reaction. Proc. Combust. Inst. 2009, 32 (1), 149-155.

40. Goldsmith, C. F.; Magoon, G. R.; Green, W. H., Database of Small Molecule Thermochemistry for Combustion. J. Phys. Chem. A 2012, 116 (36), 9033-9057.

41. Frisch, M. J.; Trucks, G. W.; Schlegel, H. B.; Scuseria, G. E.; Robb, M. A. et al., Gaussian 09 Revision D.01. Gaussian, Inc., Wallingford CT, 2009.

42. Gonzalez, C.; Schlegel, H. B., An improved algorithm for reaction path following. J. Chem. Phys. 1989, 90 (4), 2154.

43. Gonzalez, C.; Schlegel, H. B., Reaction path following in mass-weighted internal coordinates. $J$. Phys. Chem. 1990, 94 (14), 5523-5527.

44. Glasstone, S. L., K. J.; Eyring, H., The Theory of Rate Processes. McGraw-Hill: New York: 1941.

45. Steinfeld, J. I., Chemical kinetics and dynamics. 2nd ed.; Prentice Hall: Upper Saddle River, N.J. : 1999. 
46. McQuarrie, D. A., Statistical Thermodynamics. University Science Books: Mill Valley, CA: 1973. 47. Malcolm, C.; NIST-JANAF, Thermochemical Tables-Fourth Edition, J. of Phys. and Chem. Ref. Data, Monograph No. 9, 1998.

48. J. R. Barker, T. L. N., J. F. Stanton, C. Aieta, M. Ceotto, F. Gabas, T. J. D. Kumar, C. G. L. Li, L. L. Lohr, A. Maranzana, N. F. Ortiz, J. M. Preses, J. M. Simmie, J. A. Sonk, and P. J. Stimac MultiWell2017 Software Suite, 2017; 2017.

49. Jodkowski, J. T.; Rayez, M.-T.; Rayez, J.-C.; Bérces, T.; Dóbé, S., Theoretical Study of the Kinetics of the Hydrogen Abstraction from Methanol. 2. Reaction of Methanol with Chlorine and Bromine Atoms. J. Phys. Chem. A 1998, 102 (46), 9230-9243.

50. Ruscic, B.; Bross, D. H., Active Thermochemical Tables (ATcT) values based on ver. 1.122d of the Thermochemical Network. 2018.

51. Sosa, C.; Bernhard Schlegel, H., Ab initio calculations on the barrier height for the hydrogen addition to ethylene and formaldehyde. The importance of spin projection. Int. J. Quantum Chem. 1986, 29 (4), 1001-1015.

52. Montoya, A.; Truong, T. N.; Sarofim, A. F., Spin contamination in hartree- fock and density functional theory wavefunctions in modeling of adsorption on graphite. J. Phys. Chem. A 2000, 104 (26), 6108-6110.

53. Cioslowski, J.; Liu, G.; Martinov, M.; Piskorz, P.; Moncrieff, D., Energetics and site specificity of the homolytic $\mathrm{C}-\mathrm{H}$ bond cleavage in benzenoid hydrocarbons: An ab initio electronic structure study. $J$. Am. Chem. Soc. 1996, 118 (22), 5261-5264.

54. Pople, J. A.; Gill, P. M.; Handy, N. C., Spin-unrestricted character of Kohn-Sham orbitals for openshell systems. Int. J. Quantum Chem. 1995, 56 (4), 303-305.

55. Hippler, H.; Troe, J., Thermodynamic properties of benzyl radicals: enthalpy of formation from toluene, benzyl iodide, and dibenzyl dissociation equilibria. J. Phys. Chem. 1990, 94 (9), 3803-3806.

56. Luo, Y.-R., Comprehensive handbook of chemical bond energies. CRC press: 2007.

57. Somers, K. P.; Simmie, J. M., Benchmarking compound methods (CBS-QB3, CBS-APNO, G3, G4, W1BD) against the active thermochemical tables: formation enthalpies of radicals. J. Phys. Chem. A 2015, 119 (33), 8922-8933.

58. Zádor, J.; Taatjes, C. A.; Fernandes, R. X., Kinetics of elementary reactions in low-temperature autoignition chemistry. Prog. Energ. Combust. 2011, 37 (4), 371-421.

59. Ryzhkov, A.; Ariya, P.; Raofie, F.; Niki, H.; Harris, G., Theoretical and experimental studies of the gas-phase Cl-atom initiated reactions of benzene and toluene. Adv. Quantum Chem. 2008, 55, 275-295.

60. Uc, V. H.; Alvarez-Idaboy, J. R.; Galano, A.; García-Cruz, I.; Vivier-Bunge, A., Theoretical determination of the rate constant for $\mathrm{OH}$ hydrogen abstraction from toluene. J. Phys. Chem. A 2006, 110 (33), 10155-10162.

61. Deb, D. K.; Sarkar, B., Formation of Criegee intermediates and peroxy acids: a computational study of gas-phase 1, 3-cycloaddition of ozone with catechol. Phys. Chem. Chem. Phys. 2019, 21 (27), 1458914597. 